\title{
How to Think about Health Promotion Ethics
}

\author{
Stacy M. Carter, BAppSci, MPH(Hons), PhD, ${ }^{1}$ \\ Alan Cribb, BA, $\mathrm{PhD},{ }^{2}$ \\ John P. Allegrante, BS, MS, $\mathrm{PhD}^{3,4}$
}

\begin{abstract}
Health promotion ethics is moral deliberation about health promotion and its practice. Although academics and practitioners have been writing about ethics, and especially values, in health promotion for decades, health promotion ethics is now regaining attention within the broader literature on public health ethics. Health promotion is difficult to define, and this has implications for health promotion ethics. Health promotion can be approached in two complementary ways: as a normative ideal, and as a practice. We consider the normative ideal of health promotion to be that aspect of public health practice that is particularly concerned with the equity of social arrangements: it imagines that social arrangements can be altered to make things better for everyone, whatever their health risks, and seeks to achieve this in collaboration with citizens. This raises two main ethical questions. First: what is a good society? And then: what should health promotion contribute to a good society? The practice of health promotion varies widely. Discussion of its ethical implications has addressed four main issues: the potential for health promotion to limit or increase the freedom of individuals; health promotion as a source of collective benefit; the possibility that health promotion strategies might "blame the victim" or stigmatise those who are disabled, sick or at higher risk of disease; and the importance of distributing the benefits of health promotion fairly. Different people will make different moral evaluations on each of these issues in a way that is informed by, and informs, their vision of a good society and their understanding of the ends of health promotion. We conclude that future work in
\end{abstract}

\footnotetext{
${ }^{1}$ NHMRC Career Development Fellow, Centre for Values, Ethics and the Law in Medicine, School of Public Health, The University of Sydney, Australia.

${ }^{2}$ Professor of Bioethics and Education, Centre for Public Policy Research, King's College, London, UK.

${ }^{3}$ Professor of Health Education and Deputy Provost, Teachers College, Columbia University, USA.

${ }^{4}$ Adjunct Professor of Sociomedical Sciences in Public Health, Mailman School of Public Health, Columbia University, USA.
}

Corresponding Author Contact Information: Stacy M. Carter at stacy.carter@sydney.edu. au; NHMRC Career Development Fellow, Centre for Values, Ethics and the Law in Medicine, School of Public Health, The University of Sydney, NSW 2006, Australia. 
health promotion ethics will require thoughtfully connecting social and political philosophy with an applied, empirically informed ethics of practice.

Key Words: Ethics, health education, health promotion, moral philosophy, political philosophy, public health

Suggested Citation: Carter SM, Cribb A, Allegrante JP. How to think about health promotion ethics. Public Health Reviews. 2012;34: epub ahead of print.

\section{HOW TO THINK ABOUT HEALTH PROMOTION ETHICS}

Ethics is the discipline devoted to moral reasoning about what we should do. It is traditionally divided into: meta-ethics, concerned with fundamental questions like "what is good?" and "what are convincing ethical arguments?"; normative ethics, focused on rules, frameworks or principles for evaluation; and practical ethics, concerned with the ethics of practices such as regulating, policing, teaching or medical care ${ }^{1}$ Health promotion ethics is a form of practical ethics.

A substantial literature in bioethics - the practical ethics of medicine and biotechnology - has existed since the 1960s. ${ }^{2}$ The public health ethics literature grew rapidly from $2000,{ }^{3-13}$ initially focused on crises such as pandemics and bioterrorism. ${ }^{14} \mathrm{~A}$ small formal and informal literature on health promotion ethics ${ }^{15-22}$ and values ${ }^{23-27}$ has existed for some time, ${ }^{i}$ but has recently regained attention within public health ethics. Our purpose is to survey key issues in health promotion ethics, and suggest approaches needed for this field to flourish.

Defining health promotion is notoriously difficult. ${ }^{26,29-32}$ In some jurisdictions health promotion is an occupational category, so health promotion could be "what those practitioners do." But many others promote health, within and beyond public health and medical systems, and health promotion ethics should arguably also be relevant to them. Complicating matters further, conditions that $d o$ promote health may not be implemented to promote health. ${ }^{33}$ Public transportation, urban design and the structure of markets can promote or undermine health without that intention; a country's political culture and system can influence the determinants of health independent of a formal "health promotion" sector. ${ }^{34,35}$ This makes a discussion of health promotion ethics slippery: should we focus only on activities defined as health promotion, or should we include all activities

\footnotetext{
i Practitioners' extensive debate about values in health promotion has often occurred in online forums, so may not be captured in the literature. ${ }^{28}$
} 
that promote health ${ }^{33}$ Finally, the boundaries between health promotion and the rest of public health are unclear, so health promotion ethics and public health ethics may not be meaningfully different. There is no absolute solution to these problems: we can only suggest a working conception of health promotion. To do this, we will distinguish between health promotion as a normative ideal, and health promotion as it is practiced. These can, but do not always, overlap.

The normative ideal of health promotion arises from a 30-year-old discourse, found in the Alma-Ata Declaration, the World Health Organization (WHO) "Global Strategy for Health for All by the Year 2000," and the Ottawa Charter for Health Promotion. ${ }^{23,36,37}$ Bauman and colleagues suggest that Alma-Ata and "Health for All" created health promotion out of health education, ${ }^{\text {,i }}$ promoting a then-radical account of health as more a product of social conditions than of clinical services, and emphasising equity, empowerment and justice. ${ }^{26,29,38,39}$ The Ottawa Charter powerfully asserted this account, listing "fundamental conditions and resources for health" as "peace, shelter, education, food, income, a stable eco-system, sustainable resources, social justice, and equity." ${ }^{23}$ We think this ideal form of health promotion has two main distinguishing characteristics. The first is its vision of citizens: as active participants in and potential authors of their own health, people with whom health promotion practitioners should work directly and, to some extent, be guided by when forming goals and strategies. The second is its focus on increasing the equitable availability of the conditions and resources that improve health, including through structural change and advocacy.iii,34 Although this will at times overlap with risk reduction strategies, it emphasises primary prevention: promoting health for everyone, whether they are at low or high risk of developing disease. ${ }^{43}$ On this idealised account, health promotion becomes that aspect of public health practice that is particularly concerned with the equity of social arrangements: it imagines that social arrangements can be altered to make things better for everyone, whatever their health risks, and seeks to achieve this in collaboration with citizens.

As it is impossible to cleanly separate health promotion from other aspects of public health, much of what follows will be relevant to public health in general. Our idealised account of health promotion is intended to reflect its character, rather than provide a watertight definition; analysing or

\footnotetext{
ii The role of a health educator was clearer, of a health promoter looser. So it may have been easier to develop a procedural ethic for health education than for health promotion. ${ }^{20}$

iii This initial commitment may now be diluted by neoliberal individualism and behaviourism..$^{26,40-42}$
} 
defending it in detail is beyond the scope of this paper. Instead we will focus on two underlying ethical questions:

1. What is a good society?

2. What should health promotion contribute to a good society?

These questions are relevant to practitioners, but also to anyone interested in health as a moral concern, or in health promotion as a political or social enterprise.

The practice of health promotion varies globally and is not always consistent with the idealised account. ${ }^{26,43,44}$ Because practice cannot be predicted from the ideal, health promotion ethics needs to engage the diversity of health promotion practices. Thus, in the latter part of the paper, we ask a third question: What ethical issues arise in activities intended to promote health? Answers to this question are relevant to anyone who attempts to improve the health of communities, including health promotion practitioners.

\section{WHAT IS A GOOD SOCIETY?}

Here we present an abridged account of some versions of the good society that appear in the public health and health promotion ethics literature. Most of these draw on political or moral philosophy. They are relevant because the intention to promote health or related good things can only be evaluated against our conception of a good society.

In one version of the good society, the population as a whole is made as healthy as possible using available resources. This utilitarian view prioritises maximising population health without much concern about who benefits or misses out. An alternative good society, strongest in American scholarship, emphasises the liberty of citizens as the most important good. This vision arises from libertarianism and some forms of liberalism, and only condones interventions designed to stop individuals from harming each other. ${ }^{45}$ Another tradition, "justice as fairness," builds on the work of John Rawls to focus on fair distribution of good things (whether health, quality of life, wellbeing, money or opportunities), with a particular concern for the least well-off. ${ }^{46}$ Yet another good society, drawing on classical Greek scholarship, emphasises the ability of citizens to participate actively in local civic life and live in accordance with their values ${ }^{47} \mathrm{~A}$ tradition in Western European scholarship emphasises solidarity-willingness to stand together, share burdens and help one another-as an important characteristic of a good society ${ }^{48,49}$ Although we have disaggregated these visions to clarify their differences, in practice they often overlap or cluster. The normative ideal of health promotion corresponds to certain visions of the good society, 
particularly to the idea that a good society is a just society. The Ottawa Charter, for instance, strongly asserts the importance of equity. ${ }^{23}$ The ideal also resonates with traditions that emphasise civic virtue and solidarity. However, because ideals and practices are not always aligned, none of these values can be taken for granted in practice. ${ }^{42,43}$

\section{WHAT SHOULD HEALTH PROMOTION CONTRIBUTE TO A GOOD SOCIETY?}

What should the goals of health promotion be? Or: what should health promotion contribute to a good society? The answer might seem obvious: health promotion should promote health, so what health promotion should contribute to a good society is improved health.

This is not straightforward, however, because there is little agreement about how health should be defined. ${ }^{38}$ We discuss definitions of health in this section not to derive the perfect definition, but because a useful working definition is needed, for two reasons ${ }^{29}$ First: so health can be distinguished from other good things, to allow precision about goals. When are we seeking to improve health? When to provide different good things? How is health related to these other good things? Second: so that activities that either promote health or are intended to promote health can be identified, because these, at least in one sense, constitute health promotion.

In the late 1970s, definitions of health were divided into two main camps: "negative" and "positive". ${ }^{29,30,50}$ Christopher Boorse sought to develop a value-free, or "biostatistical" definition, ${ }^{51}$ based on functions such as reproduction or survival. Those with "functional abilities below typical efficiency" were diseased; ${ }^{51}$ health was the absence of such disease (thus a "negative" definition) ${ }^{\text {iv }}$ On this definition, health promotion would entail, e.g., finding individuals with below-typical reproductive function, and improving their function to typical levels. In stark contrast, the 1978 Declaration of Alma-Ata applied the WHO's 1946 "positive" definition of health as "a state of complete physical, mental and social wellbeing, and not merely the absence of disease or infirmity." ${ }^{\prime 6,53, v}$ On this definition,

\footnotetext{
iv This account is much criticised (e.g., as relying on relative judgements and ignoring things we commonly understand as health). ${ }^{29,52}$

${ }^{v}$ This account is also much criticised: e.g., Bok argues "it has been variously called masterful or dysfunctional, profound or meaningless; defended as indispensable in its present formulation, seen as needing revision, or rejected as inviting the medicalization of most of human existence and abuses of state power in the name of health promotion." ${ }^{54}$
} 
health promotion is charged with enabling every citizen to attain complete wellbeing. ${ }^{26}$ This stirring aspiration is an impossible task, and set health promotion up for an inevitable gap between rhetoric and practice. . $^{55 \mathrm{vi}}$

More recent "mid-range" or "welfare" definitions of health sit between the negative biostatistical and positive wellbeing accounts. ${ }^{29,30}$ In the late 1980s, Lennart Nordenfelt defined health as the ability to "fulfil vital goals." ${ }^{\circ 6}$ Vital goals were those that, when fulfilled, allowed a person to experience a minimum acceptable degree of welfare in the long term. . $^{\text {viviviii }}$ David Seedhouse, later but similarly, defined health as the conditions that allowed people to work towards, or to fulfil, their "realistic chosen and biological potentials." ${ }^{18}$ His main point was that health promotion must accept an open-ended conception of health: ${ }^{59}$ health will be different for each person, because each person's chosen potential is different, reflecting their values. These definitions, admirably, allow space for individuals to live the life they choose. But they are practically problematic. They would require that health promotion either employ strategies compatible with

\footnotetext{
${ }^{v i}$ David Buchanan wrote extensively about wellbeing as an end in health promotion. ${ }^{47}$ In philosophy, an "end" is good in itself; a "means" is good because it will get you something else that is good. Buchanan critiqued the WHO definition for conflating health and wellbeing, and for suggesting health was an end in itself. Health, he argued, is an instrumental good like money: simply a means to greater ends, not to be pursued for its own sake. Buchanan proposed we should strive not for health, but for eudaimonia, a complex concept from classical Greek scholarship, which involves the ability to evaluate one's own desires. "The good life" Buchanan argues, "is the life spent seeking clearer understandings of values we think important to realise and striving to live our lives more closely attuned to those values." ${ }^{47}$ What matters is to cultivate, in citizens, the mindfulness and wisdom required to continuously consider their own values and live in keeping with them. Buchanan makes this argument to resist what he sees as the rise of scientifically defined, individualistic, biomedical goals in health promotion, an over-emphasis on bodily health as an end in itself rather than a means. Buchanan's theory is inspiring, with much to offer, but does not clarify why health promotion should be the institution charged with the monumental goal of creating wise citizens.

vii This introduces normative questions, e.g.: What should count as a vital goal? What level of welfare is an acceptable minimum? Might we underestimate this minimum because we have lowered our expectations? Who gets to decide?

viii Venkatapuram recently combined Nordenfelt's account with Nussbaum's work to define vital goals. Nussbaum argued that a dignified human life required the ability to achieve all of the following, to a reasonable threshold: life, bodily health, bodily integrity (i.e., freedom from torture and other violence), to be able to use one's senses, imagination, thought and emotions, to be able to reason about one's life goals, to have opportunity for sympathetic bonds with other humans and concern towards other species, to be able to play, and to have control over one's environment. Venkatapuram proposed that these can be thought of as vital goals: thus health is the ability to achieve a reasonable threshold of each of them. However, like the WHO definition, this account is extremely broad, so may not help distinguish the goals of health promotion from those of other practices, or health policy from public policy in general..$^{52,57}$
} 
everyone's goals or potentials - likely to be impossible-or so tailored to individual goals that health promotion could only be delivered in a one-toone relationship, and could no longer engage in advocacy, structural or community-level change.

More recently other authors-Alan Cribb ${ }^{29}$ and Madison Powers and Ruth Faden ${ }^{60}$ - have produced definitions that better distinguish health from competing goods, and thus better identify health-promoting activities. We will characterise these definitions as useful, restricted and contextualised. Cribb summarises like this:

"It seems to me that if we stick fairly close to the biomedical conception [of health] but combine aspects of wider conceptions with it we get close to a workable model of health which allows us to prevent some of the extremes of indeterminacy. I tend to use "health" to refer to "the absence of illness" where illness refers roughly to the object of healthcare practice rather than that of clinical science..." 29

Cribb's, and Powers and Faden's, definitions have similar characteristics. They are useful, rather than absolute. They restrict health to the domains of the body and the objects of healthcare (loosely, what health means in ordinary language). And they connect this narrower definition to a context. Cribb argues that health must be understood as social and as only one of many "goods". Health policy is part of public policy more broadly and is likely to deliver benefits other than health, and health must be weighed against other gains from policy decisions. Health is also social: it is socially determined, understood in a social and historical context, and negotiated in social relationships. ${ }^{29}$ Thus we can retain a narrow definition of health but recognise it is socially caused and connected. Powers and Faden, meanwhile, set their restricted definition of health into a broader definition of human wellbeing. Health, for them, is just one of six dimensions of wellbeing: the other five are: personal security, reasoning, respect, attachment and selfdetermination. Everyone, they propose, has something like a fundamental right to achieve a sufficient threshold of each of these dimensions: a just society will provide this. The role of public institutions is to serve social justice, that is, to work towards sufficient wellbeing, in each of its six dimensions, for everyone. ${ }^{\text {ix }}$ Individual public institutions might specialise in one dimension (e.g., health), but they must, overall, be committed to social justice, which means that they should not promote their "specialist" dimension while undermining other dimensions (e.g., they should not encourage disrespect for obese people to improve population health). ${ }^{60}$ This approach discourages blindly pursuing population health as an end in itself. ${ }^{47}$

${ }^{\text {ix }}$ Like Nordenfelt's definition, this raises the question of how such a threshold can be identified. 
These recent definitions of health suggest an overarching goal and a more specific objective for health promotion practice. The overarching goal would be to help ensure sufficient wellbeing in all its dimensions for everyone (that is, to work for social justice). ${ }^{60, x}$ The specific objective of health promotion would be to improve health, understood via a useful and restricted definition set in a social context and in the context of the other dimensions of wellbeing. Given the overwhelming evidence that health is socially as well as biologically determined, the goal of health improvement will often need to be achieved via the mechanism of broader economic and social improvement. ${ }^{61,62}$ However, a restricted definition prevents health promotion practitioners or others from doing whatever they please in the name of health, and requires at least a credible explanation of how an intervention might improve health..$^{29,61,63}$ These definitions also highlight the moral importance of considering the nonhealth consequences of health promotion actions, as health policy is only one aspect of public policy, and health should not be pursued at the expense of other dimensions of wellbeing. ${ }^{33,60}$

\section{WHAT ETHICAL ISSUES ARISE IN ACTIVITIES INTENDED TO PROMOTE HEALTH?}

Thus far we have identified broad ethical currents underlying the normative ideal of health promotion. These currents-especially those around ideas of justice and community-are arguably the core values that health promotion practitioners use to explain and justify their practices. ${ }^{43}$ We have also begun to indicate some potential gaps between ideals and practices. In particular we have argued that, when it comes to practice, the concerns with justice and community embedded in early health promotion discourses should be disentangled from an open-ended conception of health, and instead connected to a useful, restricted and contextualised conception.

In this section we focus on ethical debates in health promotion practice. These debates reflect, and feed into, the two issues we have already considered: visions of the good society, and the proper goals of health promotion. ${ }^{x i}$ Ethical discussions about the practice of health promotion can

\footnotetext{
${ }^{\mathrm{x}}$ Powers and Faden argue that public institutions are obliged to work towards justice. While health promotion may be more explicitly committed to justice in its rhetoric, in their view all aspects of public health, as a public institution, should serve justice.

xi "Reflection" is thus a two way process: answers to health promotion practice dilemmas will reflect a vision of health promotion and the good society; conversely these visions should be engaged with everyday practice.
} 
be gathered loosely under four intersecting themes, echoing the value tensions rehearsed above. Considered together, they question whether and how ideals of justice and community can be operationalised in real-world contexts without unacceptable ethical costs. Although they intersect, we will discuss them separately:

1. how health promotion might impinge on, or enhance, the freedom or autonomy of citizens;

2. health promotion as a source of collective goods or benefits;

3. victim blaming and stigmatisation; and

4. how the benefits of health promotion are distributed.

Two more general observations about ethics in health promotion practice; first, doing health promotion ethics requires using and critiquing evidence. ${ }^{64,65}$ Outcomes or consequences (especially benefits and harms) are central to ethical evaluation. However, the evidence base in health promotion, particularly regarding the effects of complex interventions, is often limited, ${ }^{64,66}$ so decisions must be taken in the context of uncertainty. Second, ethical reasoning requires more than recourse to codes of ethics. Close attention to the strengths and weakness of ethical arguments and to the meaning of concepts is needed. ${ }^{64}$ There are several codes of ethics in this field (e.g. $\left.{ }^{67-70}\right)$. Their purpose is to codify-to provide a condensed list of rules for action-and their brevity makes them useful for busy practitioners. However, they are most useful when seen as prompts to, and not substitutes for, moral deliberation.

\section{Health promotion and the freedom or autonomy of citizens}

An early and central concern in health promotion ethics, particularly in American scholarship, has been incursion on freedoms or liberties that matter to individuals. ${ }^{18,71-74}$ Individual freedom is undoubtedly morally important; this is most clearly recognised in Western liberal democracies. In clinical ethics, respect for autonomy-generally operationalised as consent-marks out this area of concern. ${ }^{75}$ But in health promotion, consent is harder to rely on: it is difficult to know what should be consented to, who should consent, and what should be done when there is no community consensus. ${ }^{33}$

Empowerment has often been suggested as a health promotion strategy to respect freedom. Here Braunack-Mayer's analysis is useful. ${ }^{84}$ She argues - consistent with our discussion above — that the proper end of health 
promotion is health improvement: empowerment is simply a means. ${ }^{\text {xii }}$ Empowerment may not be achievable; empowerment strategies may assist some community members to dominate others, or encourage them to demand ineffective or harmful interventions, a concern echoed by practitioners. ${ }^{70}$ So empowerment should not be pursued as an end in itself. Instead, expert or "top down" health promotion judgements, informed by theory and experience, should be informed by "bottom up" judgements of community groups, and vice versa, until a reflective equilibrium is reached. Empowerment thus becomes a means for reaching this equilibrium, not a go-to strategy for protecting freedom. ${ }^{84}$

So if empowerment cannot help us solve the problem of incursions on freedom, what might? The early literature in particular focused on identifying — and arguing against—actions likely to undermine freedom. These authors tend to work with a particular, limited, version of freedom, referred to as "negative freedom": the freedom to be left alone, or not to be interfered with. ${ }^{\text {xiii,78 }}$ They worry about persuasion (encouraging people to do or believe something through argument), coercion (imposing on the will of others using threats or force), or most notoriously, paternalism. Paternalism gathers several, usually three, meanings into a single word: interfering with a person's autonomy or liberty, doing so without their consent, and doing so for their own good ${ }^{\text {xiv, } 76}$ It is possible to justify all of these, depending on our view of a good society, and on the particular case..$^{45,77}$

Persuasion is the easiest action to justify. Alastair Campbell, for example, argues that persuasion can respect people's autonomy if we are clear that we are persuading, do not distort the facts, argue overtly rather than influence covertly, and remain independent of vested interests. ${ }^{79}$ Although respectful persuasion is clearly possible, many health social marketing campaigns instead engage in what Campbell calls "indoctrination," usually in the name of "cut through" in a competitive media market.

\footnotetext{
xii This parallels sociological critiques of health promotion. "Positive" sounding discourses around empowerment or enablement are often, in practice, embedded in power hierarchies, systems of surveillance and restrictive conceptions of ends. So we have to examine both ideals and practices, asking what vision of a good society they assume and what they produce in the social world.

xii Basic liberties, and non-interference in them, are very important (e.g., freedom from wrongful imprisonment or torture, and freedom of political expression.) Unfortunately arguments focused on negative freedoms tend to suggest that more trivial freedoms, such as the freedom to make unfettered consumer choices, are of equivalent moral importance to these much more significant freedoms.

xiv In political discourse paternalism is often equated with a "nanny state".
} 
Coercion is a different matter. It is generally accepted that public health interventions should use the least coercive means available, ${ }^{80}$ and for good reason: past coercive policies (e.g., forcing people to have HIV tests early in the epidemic) frequently undermined trust in public health as an institution. ${ }^{4}$ Health promotion is not immune: for example, employees might be forced to participate in a workplace health exercise program. ${ }^{16}$ So when might coercion or paternalism be justified? ${ }^{\mathrm{xv}}$ The most common allowances are in instances where interventions stop people from harming one another rather than from harming themselves (e.g., mandatory immunisation schemes to prevent hospital staff from infecting their patients and families or schoolchildren from infecting their peers), or when interventions interfere with actions that are ill-informed, or involuntary, or more controversially, not in keeping with a person's most deeply-held goals. ${ }^{38,76, x v i}$ Such conditions can be used to evaluate interventions, but they work best for those-like the workplace health program-where something is being done directly to individuals. They are less helpful for the structural, community or advocacy interventions that we have suggested might characterise health promotion. One could argue, for example, that high fat, high sugar foods should be regulated because individual consumers do not fully understand the risks, or do not mean to buy these foods, or that eating them is inconsistent with what they really want for their life. But these are difficult to demonstrate convincingly, and matter most to those, such as libertarians, who hold negative freedomthe freedom to be left alone - to be the most important moral end.

There is an alternative that is more compatible with health promotion: the capability approach. ${ }^{57,85,86}$ The capability approach contends that people should be free to achieve wellbeing, and that this relies on them having real opportunities to live and to act in accordance with their values. ${ }^{85, x v i i}$ The capability approach encourages us to assess both the opportunities available to individuals, and those available to a whole community or nation. And it approaches freedom quite differently to the approaches described above. It does not assume that individuals should be completely independent, or that their most important interest is to be left alone. Rather, it emphasises that

\footnotetext{
${ }^{x v}$ Dworkins' typology of more or less justifiable paternalisms is generally considered the standard. ${ }^{81}$

xvi In Western liberal state policy, "Nudge" is currently influential, employing an allegedly unproblematic type of paternalism, "libertarian paternalism," and based in behavioural economics and cognitive psychology ${ }^{82}$ See detailed analysis and responses in the American Journal of Bioethics. ${ }^{83}$

xvii Writers in the capabilities approach would say "to be and to do" in accordance with their values. Martha Nussbaum's list of "central capabilities" required for a dignified human life is provided in Note viii.
} 
people's autonomy depends on their social, relational and political environment, and that they have a moral stake in that environment providing them with real opportunities, including the opportunity to be healthy. Thus, for example, rather than reducing our freedom, state taxation, subsidies and regulations that make it easier and cheaper to buy healthier food could provide real opportunities to be healthy, something that most people value. Autonomy remains important, but a more sophisticated conceptualisation alters the discussion of freedom. Instead of asking "is this health promotion strategy instituting a paternalistic nanny state?" we are encouraged to ask "is this health promotion strategy providing individuals and communities with real opportunities that they are likely to value?"

\section{Health promotion as a source of collective goods or benefits}

Collective actions and collective goods have particular moral significance for health promotion, because its ideal form has emphasised community. This emphasis appears to be a present source of tension in health promotion. Health promotion is commonly criticised for becoming increasingly individualistic, ${ }^{26,40-42,88}$ simultaneously practitioners affirm their commitment to working with and for communities. . $3370^{2}$

We will deal with individualism in the next section, but first consider arguments regarding the moral significance of community. There is a long tradition of valuing community in political and moral philosophy; this is becoming increasingly prominent in public health and health promotion ethics. ${ }^{89,90}$ It reflects a vision of the good society in which shared values, the common good or solidarity are important and, as in the capability approach, people are thought of as potentially benefiting from, not just being threatened by, the fact that they live in a community.

This is, in part, about the existence and benefit of collective goods. There is a type of collective good that is simply the sum of individual goods (e.g., a lower average HIV prevalence in the population is the sum of many individuals not having HIV). But there is another kind of collective good that is greater than the sum of its parts: goods that can only exist through collective action, and which exist at a collective level. Widdows and Cordell suggest that these goods can be identified as the ones that we think of as

\footnotetext{
xviii Libertarians often suggest that the only way to preserve consumer freedom is to limit intervention to information provision (e.g., food package labelling). The capabilities approach suggests that having to carefully analyse the labels of every food product to determine whether it is unhealthy is in fact a burden. Regulation to reformulate food and/or restructure the market to allow people of all levels of ability and wealth the opportunity to purchase healthy food easily would provide a more meaningful freedom. ${ }^{87}$
} 
"its" goods, that is, the goods of "the community" as a whole, as opposed to "their" goods, that is the goods of the individuals who live in the community ${ }^{89}$ So, for example, if we say "West Haven is a walkable city" or "France has high quality, affordable childcare services" or "Denmark's food supply contains almost no transfats," we are talking about goods that accrue to the entire community, to the body politic. Most importantly, they are goods that individuals cannot achieve for themselves: they can only be achieved through collective action. They are also better seen as opportunities (in the capabilities sense) rather than interferences. And the ideal form of health promotion discussed above is particularly well-oriented towards such goods. Because these goods have special moral significance, this suggests that in evaluating health promotion activities we might ask: "Will this benefit everyone?" and "Are we focusing on outcomes that can only be achieved through collective action?"

\section{Victim blaming and stigmatisation}

Individualism, and collective goods, can be connected by considering the wrongs that health promotion might do to people and communities. ${ }^{\text {xix }}$ In short, health promotion practice seems likely to do wrong when it is methodologically individualistic, that is, when it understands social phenomena as largely a product of individual agency, of the goals, beliefs and actions of individuals, rather than focusing on collective goods and actions. ${ }^{44,88,91}$ This entails an oversimplified model of disease and risks two main wrongs: victim blaming and stigmatisation. ${ }^{\mathrm{xx}}$

The potential for health promotion to "blame the victim" has been a longstanding concern in health promotion ethics..$^{92,93}$ This expresses an important worry: is it just to consider individuals personally responsible for their health? As with all moral issues, a view of individuals as personally responsible tends to travel with a particular view of the good society, one that imagines people as fully rational, informed and in control of their lives, and thus values the protection of their negative freedom as a crucially important moral good.

\footnotetext{
xix Unjustifiably interfering in someone's freedom, already considered, is also a wrong.

${ }^{\mathrm{xx}}$ Note that victim blaming and stigmatisation are important wrongs, but not the only wrong we should be concerned about: e.g., in an American setting, employers may buy-in health promotion programs and then cut health insurance cover on the grounds that employees should be healthier. ${ }^{16}$ Each strategy needs to be considered case by case. Also: victim blaming and stigmatisation are widespread social trends. We are suggesting not that health promotion practitioners are especially guilty of them, but that they are especially obligated to avoid them because they are inconsistent with the goals and values of health promotion.
} 
There are two key points to make here. The first is to distinguish causal from moral responsibility. We might, for example, prepare a meal for our family and in so doing unwittingly give them food poisoning; in this case we would be causally, but not morally, responsible. ${ }^{29}$ The second point to make is that there is no clear line between private and public actions in health: the strong evidence on social determinants shows that responsibility for health is diffuse. ${ }^{29,62}$ We all engage in practices that contribute to our health, but at best are only partially responsible for our health status. Further, empirical evidence shows that people tend to allocate responsibility to individuals to make sense of health problems, so we may be less likely to recognise this when it occurs. ${ }^{x i, 16,94}$

Many health promotion strategies may risk allocating responsibility unjustly. Workplace-based health promotion, for example, may give employees tools to endure a health-undermining workplace rather than attempting to change the institution. ${ }^{16}$ Social marketing campaigns frequently address viewers as individuals, exhorting them to change their behaviour and suggesting that this is easy despite the overwhelming evidence to the contrary. ${ }^{64,95,96}$ Given that these campaigns are widely thought to act on social norms, they arguably reproduce the tendency for members of the general public to unjustly allocate responsibility for health risks or diseases to individuals.

The second potential wrong is that negative messages about disabilities, illnesses or risks will increase the stigma experienced by people who are already living with those disabilities, illnesses or risks. ${ }^{64,97}$ Identification and labelling of differences between people can be benign, but become stigmatising when certain identified groups are stereotyped and perceived as other-as "not like us" or deviant—leading to loss of status and systematic discrimination against people living with conditions such as mental illness or obesity. ${ }^{44,98}$

Health experts sometimes suggest that stigma is a useful tool for population-level communications. This is consistent with simplistic healthmaximising utilitarianism: an impoverished view of the good society as one that should deliver the maximum possible amount of health on average. On this view, stigmatisation that "works" to improve health is morally acceptable. This argument is clearly ethically problematic. It focuses on the health dimension of wellbeing at the expense of other dimensions, such as respect. ${ }^{60}$ It ignores evidence that stigma makes life more miserable and

${ }^{x x i}$ Note also that the empowerment discourse may imply that individuals should be able to take charge of their health. ${ }^{92}$ 
stressful and so is likely to have direct health effects. ${ }^{98}$ It fails to recognise that being stigmatised travels with disadvantage, that stigmas tend to cluster, and that stigmatised conditions are only partly the responsibility of the individuals who experience them, such that these individuals should not be held responsible unless the other involved parties are also held responsible. ${ }^{29,44,98}$ All of these problems make such stigmatisation, whether deliberate or unintentional, unjust.

Health promotion practitioners do not always have control over the work they do. They may be deeply personally committed to building respectful relationships with communities over time, building community capabilities, and ensuring sustainability, but be required to implement standardised and potentially problematic interventions. ${ }^{43}$ Managerialism can encourage "ethics avoidance", with scientific and managerial rationality overwhelming ethical concerns. ${ }^{29,99}$ David Buchanan, who developed one of few total theories of health promotion ethics in 2000 (Note vi), reacts explicitly against such rationality. He advocates responding to local situations rather than applying standardised solutions, acknowledging the importance of being trusted by communities and building solidarity, thinking of people not as faceless aggregations of statistics, or as "targets" for punishment and reward, but as citizens who are worthy of, and stand to benefit from, respectful engagement. ${ }^{47}$ This suggests the importance of accountability to communities, ${ }^{80}$ and suggests two different sets of responsibilities in health promotion. First, planners and policymakers should aim to create programs and strategies that minimise the risk of harming or wronging citizens, whether through stigmatising them, making them falsely personally responsible, or in other ways. Second, individuals on the "front-line" of health improvement, whether in official health promotion roles or otherwise, should deal respectfully with those whom they encounter and, where practicable, critically analyse, challenge and resist policies that fall short.

\section{How to distribute the benefits of health promotion}

Our final ethical question is: how should the benefits and burdens of health promotion be distributed? Asking this entails a vision of the good society as one that fairly distributes resources, opportunities or wellbeing. Powers and Faden's theory is useful here. They argue that those in society who are least well off experience "densely woven systematic patterns of disadvantage," ${ }^{\prime \prime}$ that is, they experience many forms of disadvantage simultaneously. They are likely to have less money, poorer housing, less work and lower status work, poorer quality of education and so on, all at once. These interact and compound, worsening disadvantage. So those least well-off would require 
extraordinary good luck or heroic effort to attain even an average level of wellbeing, usually through no fault of their own. ${ }^{60}$ For Powers and Faden, this makes densely patterned disadvantage particularly unjust. Because they see public institutions as especially responsible for increasing social justice, they argue that public health and health promotion, as public institutions, are particularly obliged to intervene in severe disadvantage.

By now it should be clear that we are broadly convinced by and committed to the normative ideal of health promotion summarised earlier: focused on the fairness of social arrangements, and on achieving the conditions that underpin good health for everyone, in collaboration with communities. For us this entails a reflexive commitment to a vision of the good society that emphasises social justice and collective goods, informed not only by moral and political arguments about the nature of the good society, but also by strong evidence on the social determinants of health, ${ }^{62}$ and knowledge of health promotion practice. Others will occupy different positions: for example, a utilitarian who wants to maximise average health without too much concern for its distribution or the potential ill-effects, or a libertarian who is most concerned about negative freedom, or someone focused on eudaimonia at the level of the individual (Note vi).

We emphasise a particular way of thinking about the distribution of benefits and burdens. People are not all equally autonomous. Those who have fewer opportunities relative to their fellow citizens are not autonomous in the same way as those who have more opportunities. Someone with an excellent education, high social standing, a good job, a supportive social network, and a warm, dry home in a friendly, safe neighbourhood is autonomous in a more meaningful way than someone with none of these things. Conceptualising freedom as opportunity, and understanding health promotion as an institution obliged to increase the availability of those opportunities, encourages us to redress this unfairness. Conversely, those who would emphasise freedom as the right to be left alone would see this as an intrusion rather than a justice. We are concerned that health promotion strategies should avoid increasing the existing stigma and unjust allocation of personal responsibility that multiply disadvantaged people already experience. ${ }^{98}$ This is based in our earlier arguments that health should not be pursued at the expense of other aspects of human wellbeing. But a utilitarian author may be less concerned about these issues, and a libertarian may welcome a conception of individuals as personally responsible. Like solidarity theorists, we prefer collective actions that produce collective goods, both for their ability to redress disadvantage and their aspirational qualities. Some collective interventions-such as using national regulation to reformulate food-will benefit everyone. We think that if fairness is 
important, collective interventions that occur in settings or communitiessuch as improving urban design, transportation or the availability of fresh food markets - should be distributed at least equally, if not preferentially, to disadvantaged communities. However, those who think we have no special responsibility to the less well-off may not agree.

Goldberg argues that while we should aim to improve everyone's health, we should aim to improve poor people's health more, because they are currently bearing most of the burden. ${ }^{44} \mathrm{~A}$ simplistic utilitarian position would oppose this contention. Increase average health, the argument goes, and the least well-off will also benefit: remember Rose's famous prevention paradox. ${ }^{x i i, 100}$ We make two points here. Rose's colleagues have lately emphasised his egalitarian commitments: that he argued for structural interventions as beneficial for everyone, including the least well-off. ${ }^{100}$ And in practice, "population-level" interventions often focus on altering behavioural and biological risk factors, rather than facilitating structural and political change. Identifying and intervening in people with risk factors (e.g., overweight) tends to benefit the affluent, because they have the agency required to engage and participate. ${ }^{101,102}$

We have, anecdotally, heard decision-makers justify such interventions as "helping the people who want to be helped" and so "focusing where we can be most effective." But this is only morally acceptable via a particular vision of a good society: one in which health is a product of individual choices and fairness can be de-prioritised. In a recent International Union for Health Promotion and Education ethics forum, practitioners worried that they were rarely funded to engage in structural change or address identified needs in poor communities, but instead were expected to offer interventions that only already-advantaged people could benefit from. ${ }^{70}$ For practitioners, at least, the commitment to justice built into the normative ideal of health promotion appears to remain a central concern. But despite the ideal, health promotion practice is often dominated by individualistic interventions. ${ }^{44,88}$ Current movements in health promotion towards complexity and systems thinking may help counter this trend; ${ }^{103}$ however visionary actions from health promotion opinion leaders, changes within bureaucratic systems, and modelling from the non-government sector may be required to achieve long-term change.

\footnotetext{
xxii Rose observed that populations contain many people at low to moderate risk of developing a disease, and few at high risk of developing that disease. The prevention paradox is that greater population health improvement may be obtained via widespread small improvements in those many at low risk, rather than via dramatic change in those few at high risk.
} 


\section{CONCLUSION}

Future scholars of health promotion ethics should self-consciously work between social and political philosophy on the one hand and applied, empirically informed, ethics of practice on the other. It is important to be able to map, and debate, competing normative visions of health promotion, including but not limited to the normative ideal we have elaborated here. We should ask how such normative ideals can be defended, but also how norms change in different times and places. We need to attend to principles (such as minimising harm) but also to the contexts that shape policies, norms and practices.

Many unanswered questions with ethical implications remain for future work. What is health promotion now? Does it still exist? If so, does it bear any relation to the 1980s normative ideal? How might it be different from or similar to other aspects of public health practice, and does this matter? What should it be in future? How can we better understand collective goods or benefits, and how should we weigh potentially competing goods, such as maximising average benefit vs. fairer distribution of benefit? When can citizens be reasonably expected to stand in solidarity with others to improve everyone's health? How can we convince decision makers to attend to the potential harms of interventions as well as the benefits?

Although statements of principle and codes of practice have symbolic importance, doing practical ethics requires engagement with underlying arguments and concepts, and also with the details of everyday practice. Simple prescriptions cannot suffice because every situation is different. Examining ethical questions requires a conversation: a process of reasoning back and forth between differing views of the good society and different exercises of practical wisdom and experience. It requires openness among all parties to be transformed in the exchange. We hope that the questions we have posed in this review, and the range of answers we have presented, will spark an enlivened conversation about both health promotion and health promotion ethics, and so be of use to policy makers, practitioners and everyone concerned with the health of communities.

\footnotetext{
About the Authors: Dr. Stacy M. Carter (PhD, MPH Hons) is a NHMRC Career Development Fellow at the Centre for Values, Ethics and the Law in Medicine in the School of Public Health at the University of Sydney. Her work focuses on the ethics of public health (particularly health promotion, non-communicable disease prevention and cancer screening), and on methodology for qualitative research and empirical bioethics.

Dr. Alan Cribb (PhD) is Professor of Bioethics and Education and Co-Director of the Centre for Public Policy Research at King's College London. He has a particular interest in the interface between philosophy, social sciences and professionalism.
} 
Dr. John P. Allegrante (PhD) is Professor of Health Education and Deputy Provost at Teachers College, and Adjunct Professor of Sociomedical Sciences at the Mailman School of Public Health, Columbia University. His research focuses on health behavior, health promotion, and health outcomes in chronic disease.

Acknowledgements: Stacy Carter is funded by a National Health and Medical Research Council (NHMRC) Career Development Fellowship (1032963); research for this paper was partially supported by NHMRC Project Grant 632679.

Conflicts of Interest: None declared.

\section{REFERENCES}

1. Kerridge I, Lowe M, Stewart C. Ethics and Law for the Health Professions. 3rd ed. Annandale, NSW: The Federation Press; 2009.

2. Kass NE. An ethics framework for public health. Am J Public Health. 2001;91: 1776-82.

3. Kass NE. Public health ethics: From foundations and frameworks to justice and global public health. J Law Med Ethics. 2004;32:232-42.

4. Bayer R, Fairchild AL. The genesis of public health ethics. Bioethics. 2004;18: 473-92.

5. Callahan D, Jennings B. Ethics and public health: Forging a strong relationship. Am J Public Health. 2002;92:169-76.

6. Dawson A, Verweij M. Public Health Ethics (Journal). Oxford: Oxford University Press; 2009 ff.

7. Holland S. Public Health Ethics. Cambridge: Polity; 2007.

8. Dawson A, Verweij M, (editors). Ethics, Prevention, and Public Health. New York, NY: Oxford University Press Inc.; 2007.

9. Peckham Sa, Hann A, (editors). Public Health Ethics and Practice. Bristol: The Policy Press; 2010.

10. Anand S, Peter F, Sen A, (editors). Public Health, Ethics, and Equity. Oxford: Oxford University Press; 2004.

11. Bayer R, Gostin LO, Jennings B, Steinbock B, (editors). Public Health Ethics: Theory, Policy and Practice. New York, NY: Oxford University Press; 2007.

12. Gostin LO, (editor). Public Health Law \& Ethics. Berkeley, CA; New York, NY: University of California Press; The Milbank Memorial Fund; 2010.

13. Nuffield Council on Bioethics. Public health: ethical issues. London: Nuffield Council on Bioethics; 2007.

14. Viehbeck S, Melnychuk R, McDougall C, Greenwood H, Edwards N. Population and public health ethics in Canada: a snapshot of current national initiatives and future issues. Can J Public Health. 2011;102:410-3.

15. Faden RR, Faden AI. Preface. Health Educ Behav. 1978;6:177-9.

16. Allegrante JP, Sloan RP. Ethical dilemmas in workplace health promotion. Prev Med. 1986;15:313-20. 
17. Seedhouse D. Health: The Foundations for Achievement. 1st ed. Chichester: John Wiley and Sons; 1986.

18. Bayer R, Moreno JD. Health promotion: ethical and social dilemmas of government policy. Health Aff (Millwood). 1986;5:72-85.

19. Doxiadis S, Blaney R, (editors). Ethical Dilemmas in Health Promotion. Chichester: John Wiley \& Sons Ltd.; 1987.

20. Burdine JN, McLeroy KB, Gottlieb NH. Ethical dilemmas in health promotion - an introduction. Health Educ Q. 1987;14:7-9.

21. Legal and Ethical Work Group - Conference on Medicine in the Twenty-First Century: challenges in personal and public health promotion. Ethical guidelines for health promotion. Am J Prev Med. 1994;10(3 Suppl):47.

22. Sindall C. Does health promotion need a code of ethics? Health Promot Int. 2002;17:201-3.

23. First International Conference on Health Promotion. Ottawa Charter for Health Promotion, WHO/HPR/HEP/95.1. Ottawa: World Health Organization; 1986.

24. Downie RS, Fyfe C, Tannahill A. Health promotion : models and values. 1st ed. Oxford; New York: Oxford University Press; 1990.

25. Ritchie J. Values in health promotion. Health Promot J Austr. 2006;17:83.

26. Bauman A, O'Hara L, Signal L, Smith B, Ritchie J, et al. A perspective on changes in values in the profession of health promotion. Health Promot $\mathrm{J}$ Austr. 2007;18:3-6.

27. Allegrante JP, Barry MM, Airhihenbuwa CO, Auld ME, Collins JL, et al. Domains of core competency, standards, and quality assurance for building global capacity in health promotion: the Galway Consensus Conference statement. Health Educ Behav. 2009;36:476-82.

28. Mittelmark MB. Setting an ethical agenda for health promotion. Health Promot Int. 2008;23:78-85.

29. Cribb A. Health and the good society. Oxford: Oxford University Press; 2005.

30. Cribb A. The borders of health promotion-A response to nordenfelt. Health Care Anal. 1993;1:131-7.

31. Ridde V. Reducing social inequalities in health: public health, community health or health promotion? Promot Educ. 2007;14:63-7.

32. Tannahill A. Health promotion: the Tannahill model revisited. Public Health. 2009;122:1387-91.

33. Cribb A, Duncan P. Health Promotion and Professional Ethics. Hoboken, NJ: Blackwell Publishing; 2002.

34. Raphael D. The political economy of health promotion: part 1, national commitments to provision of the prerequisites of health. Health Promot Int. 3 November 2011; epub ahead of print. doi: 10.1093/heapro/dar084

35. Raphael D. The political economy of health promotion: part 2, national provision of the prerequisites of health. Health Promot Int. 3 November 2011; epub ahead of print. doi: 10.1093/heapro/dar058

36. International Conference on Primary Health Care. Declaration of Alma-Ata. Alma-Ata, USSR: World Health Organisation; 6-12 September 1978. 
37. World Health Organisation. Global strategy for health for all by the year 2000 . Geneva: WHO; 1981.

38. Yeo M. Toward an ethic of empowerment for health promotion. Health Promot Int. 1993;8:225-35.

39. Lalonde M. A new perspective on the health of Canadians: a working document. Ottawa: Minister of Supply and Services Canada, Government of Canada; 1974.

40. Lin V. Health promotion in Australia: twenty years on from the Ottawa Charter. Promot Educ. 2007; 14:203-8.

41. Porter C. Ottawa to Bangkok: changing health promotion discourse. Health Promot Int. 2006;22:72-9.

42. Baum F. The Commission on the Social Determinants of Health: reinventing health promotion for the twenty-first century? Crit Public Health. 2008;18: 457-66.

43. Carter SM, Klinner C, Kerridge I, Rychetnik L, Li V, Fry D. The ethical commitments of health promotion practitioners: an empirical study from New South Wales, Australia. Public Health Ethics. 2012;5:128-39.

44. Goldberg DS. Social justice, health inequalities and methodological individualism in US health promotion. Public Health Ethics. 2012. doi: 10.1093/phe/phs013

45. Jennings B. Public health and liberty: beyond the Millian paradigm. Public Health Ethics. 2009;2:123-34.

46. Rawls J. A Theory of Justice. Boston, MA: Harvard University Press; 1999, 1971.

47. Buchanan DR. An Ethic for Health Promotion: Rethinking the Sources of Human Well-Being. New York, NY: Oxford University Press; 2000.

48. Dawson A, Verweij M. Solidarity: a moral concept in need of clarification. Public Health Ethics. 2012;5:1-5.

49. Prainsack B, Buyx A. Understanding solidarity (with a little help from your friends). Public Health Ethics. 2012;5:206-10.

50. Salomon JA. Quantifying individual levels of health: definitions, concepts, and measurement issues. In: Murray CJL, Evans DB, (editors). Health Systems Performance Assessment. Geneva: World Health Organization; 2003. p.301-18.

51. Boorse C. A rebuttal on health. In: Humber JM, Almeder RF, (editors). What is disease? Totowa, NJ: Humana Press; 1997. p.1-134.

52. Venkatapuram S. Health Justice. Cambridge: Polity; 2011.

53. World Health Organisation. Constitution. New York, NY: WHO; 1946 July 22nd.

54. Bok S. Rethinking the WHO definition of health. In: Heggenhougen K, (editor). International Encyclopedia of Public Health. Elsevier Inc; 2008. p.590-7.

55. Green LW, Allegrante JP. Healthy People 1980-2020: raising the ante decennially or just the name from public health education to health promotion to social determinants? Health Educ Behav. 2011;38:558-62.

56. Nordenfelt L. On the Nature of Health: an Action-Theoretic Approach. 2nd ed. Dordrecht: Kluwer Academic Publishers; 1987/1995. 
57. Nussbaum MC. Sex \& Social Justice. New York, NY, Oxford: Oxford University Press; 1999.

58. Seedhouse D. Health: The Foundations for Achievement. 2nd ed. Chichester: John Wiley and Sons; 2001.

59. Seedhouse D. Health Promotion: Philosophy, Prejudice and Practice. 2nd ed. West Sussex, England: John Wiley \& Sons Ltd; 2004.

60. Powers M, Faden R. Social Justice: the Moral Foundations of Public Health and Health Policy. Oxford: Oxford University Press; 2006.

61. Ruger JP. Ethics of the social determinants of health. Lancet. 2004;364:1092-7.

62. Commission on Social Determinants of Health. Closing the gap in a generation: health equity through action on the social determinants of health. Final Report of the Commission on Social Determinants of Health. Geneva: World Health Organization; 2008.

63. Carter SM, Entwistle VA, McCaffery K, Rychetnik L. Shared health governance: the potential danger of oppressive "healthism". Am J Bioeth. 2011;11:57-9.

64. Carter SM, Rychetnik L, Lloyd B, Kerridge IH, Baur L, et al. Evidence, ethics, and values: a framework for health promotion. Am J Public Health. 2011;101: 465-72.

65. Tannahill A. Beyond evidence-to ethics: a decision-making framework for health promotion, public health and health improvement. Health Promot Int. 2008;23:380-90.

66. Potvin L. Should we worry about the enthusiasm toward evidence-based health promotion practices? Promot Educ. 2006;13:228-9.

67. Center for Health Leadership \& Practice, Public Health Institute, Public Health Leadership Society Ethics Work Group, Public Health Leadership Society standing committee on Public Health Ethics. Principles of the Ethical Practice of Public Health. New Orleans, LA: Public Health Leadership Society; 2002.

68. Code of ethics for the health education profession. Coalition of National Health Education Organizations; 8 February 2011. Available from URL: http:// www.cnheo.org/ethics.htm (Accessed 20 December 2012).

69. Views on health promotion online. Health promotion code of ethics. Saint-Denis Cedex, France: International Union for Health Promotion and Education; 2008 (updated 27 October 2008; cited 2009 October 16).

70. Nchogu S, Bull T. Summary report for VHPO stream of discussion on ethics. Views on health promotion online website: International Union for Health Promotion and Education; No date. Available from URL: http://vhpo.net/ download/file.php?id=8\&sid=c9faf04e4d0149452dcb4eee0eef95d4 (Accessed 20 December 2012).

71. Wikler DI. Coercive measures in health promotion: can they be justified? Health Educ Behav. 1978;6:223-41.

72. Wikler DI. Persuasion and coercion for health: ethical issues in government efforts to change life-styles. Milbank Mem Fund Q Health Soc. 1978;56:303-38.

73. Faden RR, Faden AI. Ethics of health education as public health policy. Health Educ Monogr. 1978;6:180-97. 
74. Faden RR. Ethical issues in government sponsored public-health campaigns. Health Educ Q. 1987;14:27-37.

75. Beauchamp TL, Childress JF. Principles of Biomedical Ethics. Cary, NC: Oxford University Press USA; 2008.

76. Nys T. Public health paternalism: continuing the dialogue. Public Health Ethics. 2009;2:294.

77. Jones MM, Bayer R. Paternalism its discontents - motorcycle helmet laws, libertarian values, and public health. Am J Public Health. 2007;97:208-17.

78. Carter SM, Kerridge I, Sainsbury P, Letts JK. Public health ethics: informing better public health practice. N S W Public Health Bull. 2012;23:101-6.

79. Campbell A. Education or indoctrination: the issue of autonomy in health education. In: Doxiades SA, (editor). Ethics in Health Education. Chichester: Wiley; 1990. p.15-28.

80. Upshur REG. Principles for the justification of public health intervention. Can J Public Health. 2002;93:101-3.

81. Dworkin G. Paternalism. In: Zalta EN, (editor). The Stanford Encyclopedia of Philosophy (Summer 2010). Available from URL: http://plato.stanford.edu/ archives/sum2010/entries/paternalism/ (Accessed 20 December 2012).

82. Thaler RH, Sunstein CR. Nudge. New York, NY: Penguin Books; 2009.

83. Blumenthal-Barby JS, Burroughs H. Seeking better health care outcomes: the ethics of using the "nudge". Am J Bioethics. 2012;12:1-10.

84. Braunack-Mayer A, Louise J. The ethics of community empowerment: tensions in health promotion theory and practice. Promot Educ. 2008;15:5-8.

85. Robeyns I. The Capability Approach: a theoretical survey. J Human Dev. 2005;6:93-117.

86. Sen A, Nussbaum MC, (editors). The Quality of Life. Oxford: Clarendon Press; 1993.

87. Sen A. Inequality Re-examined. Boston, MA: Harvard University Press; 1992.

88. Golden SD, Earp JA. Social ecological approaches to individuals and their contexts: twenty years of health education \& behavior health promotion interventions. Health Educ Behav. 2012;39:364-72.

89. Widdows H, Cordell S. Why communities and their goods matter: illustrated with the example of biobanks. Public Health Ethics. 2011;4:14-25.

90. Beauchamp DE. Community - the neglected tradition of public health. Hastings Cent Rep. 1985;15:28-36.

91. Azetsop J, Rennie S. Principlism, medical individualism, and health promotion in resource-poor countries: can autonomy-based bioethics promote social justice and population health? Philos Ethics Humanit Med. 2010;5:1.

92. Allegrante JP, Green LW. When health policy becomes victim blaming. N Engl J Med. 1981;305:1528-9.

93. Maclean U. Health promotion - the value and virtue of health. Med Educ. 1984;18:311-3.

94. Thompson L, Kumar A. Responses to health promotion campaigns: resistance, denial and othering. Crit Public Health. 2011;21:105-17. 
95. Guttman N, Ressler WH. On being responsible: ethical issues in appeals to personal responsibility in health campaigns. J Health Commun. 2001;6:11736.

96. Swinburn B, Egger G, Raza F. Dissecting obesogenic environments: the development and application of a framework for identifying and prioritizing environmental interventions for obesity. Prev Med. 1999;29:563-70.

97. Puhl RM, Heuer CA. The stigma of obesity: a review and update. Obesity. 2009;17:941-64.

98. Link BG, Phelan JC. Stigma and its public health implications. Lancet. 2006;367:528-9.

99. Cribb A. Why ethics? What kind of ethics for public health? In: Peckham S, Hann A, (editors). Public Health Ethics and Practice. Bristol: The Policy Press; 2010. p.17-32.

100. Rose G, Khaw K-T, Marmot M. Rose's Strategy of Preventive Medicine Updated Edition. Oxford: Oxford University Press; 2008.

101. Capewell S, Graham H. Will cardiovascular disease prevention widen health inequalities? PLoS Med. 2010;7:e1000320.

102. Buck D, Frosini F. Clustering of unhealthy behaviours over time: implications for policy and practice. London: The King's Fund; 2012. Available from URL: http://www.kingsfund.org.uk/publications/clustering-unhealthy-behavioursover-time (Accessed 20 December 2012).

103. Hawe P, Shiell A, Riley T. Complex interventions: how "out of control" can a randomised controlled trial be? BMJ. 2004;328:1561-3. 